\title{
Project Scenario of Communication Network using Cisco Packet Tracer
}

\author{
Mohammed K. Yousif \\ Northern Technical University, \\ Mosul, Iraq
}

\author{
Samaa K. Al-Saffar \\ Mosul University, \\ Mosul, Iraq
}

\begin{abstract}
In today's world, Networking have become extremely necessary for providing e-mail, telnet, chat and others services. In these services, computer networks play very important role to communicate, administrate, automat and process the information from point to another points. Hence Computer networks considered the basics of proper functionally in most of the companies and organizations. In this paper, cisco pocket tracer is used as a network simulator tools to simulate and design a network project of company. The paper discussed interconnection between routers, switches and other components in data communication network and how are programmed and configured.
\end{abstract}

\section{Keywords}

Pocket tracer, router, switch, VTP, simulator, IP phones, servers, DHCP, VLAN

\section{INTRODUCTION}

Computer network can be defined as a number of computer systems and other computing hardware devices that linked together for sharing information in form massage, files, data bases in organization that may be in one building or spread over large campus [1] [2][3]. In addition to that the networks decrease cost, time, effort and thereby increase productivity [1][4]. Network connections devices are connected together by using any type of communication media such as the copper coaxial cable, twisted pair cable, fiber optic cable and wireless. While the network devices include Network interface cards (NIC), Hubs, Switches, Bridges, Routers, Gateways and Modems. Each one of these devices has various properties than others from jobbing, security and application [1][5][6].

This paper is highlighted on the VLANs (Virtual Local Area Network) and VTP (VLAN Tracking Protocol) switch as well as EIGRP (Enhanced Interior Gateway Routing Protocol). VLAN is simply a subset of switch ports that are formed to be in the same broadcast domain. Switch ports can be assembled into different VLANs on a single switch and on multiple interconnected switches as well. By creating multiple VLANs, the switches create multiple broadcast domains. Whereas VTP allows you to add, delete, and rename VLANs on a single switch and this information is then propagated to all other switches in the VTP domain [4] EIGRP is a Cisco proprietary classless routing protocol that is essentially an enhanced distance vector protocol.

Cisco Packet Tracer (CPT) is a multi-tasking network simulation software that can be used to perform and analyze various network activities such as implementation of different topologies, selection of optimum path based on various routing algorithms, creation of appropriate servers, subnetting, and analysis of various network configuration and troubleshooting commands [2][5][7][8]

\section{PROJECT NETWORK SCENARIO}

The scenario of the project assumes the company has three branches in three different locations. Each branch consist of three buildings where each building has three floors and each floor contains three switches, where the connection between them is a mesh topology as shown in figure (1). The staff distribution in the whole company as explained in table (1).

Table (1): The Distributed of the Staff in Company

\begin{tabular}{|c|c|c|c|c|}
\hline Name & $\begin{array}{c}\text { Number } \\
\text { of staffs }\end{array}$ & $\begin{array}{l}\text { Network } \\
\text { address }\end{array}$ & $\begin{array}{l}\text { Broadcas } \\
t \text { address }\end{array}$ & $\begin{array}{c}\text { Subnet } \\
\text { mask }\end{array}$ \\
\hline $\begin{array}{l}\text { Number of } \\
\text { engineers }\end{array}$ & 300 & 10.0 .0 .0 & $\begin{array}{c}10.0 .1 .25 \\
5\end{array}$ & 23 \\
\hline $\begin{array}{l}\text { Number of } \\
\text { accountants }\end{array}$ & 250 & 10.0 .2 .0 & $\begin{array}{c}10.0 .2 .25 \\
5\end{array}$ & 24 \\
\hline $\begin{array}{l}\text { Number of } \\
\text { salesmen }\end{array}$ & 200 & 10.0 .3 .0 & $\begin{array}{c}10.0 .3 .25 \\
5\end{array}$ & 24 \\
\hline $\begin{array}{l}\text { Number of } \\
\text { workers }\end{array}$ & 80 & 10.0 .4 .0 & $\begin{array}{c}10.0 .4 .12 \\
7 \\
\end{array}$ & 25 \\
\hline $\begin{array}{l}\text { Number of } \\
\text { chairmen }\end{array}$ & 9 & 10.0 .5 .0 & 10.0 .5 .15 & 28 \\
\hline $\begin{array}{l}\text { Number of } \\
\text { assistance } \\
\text { chairmen }\end{array}$ & 9 & 10.0 .6 .0 & 10.0 .6 .15 & 28 \\
\hline $\begin{array}{l}\text { Number of } \\
\text { phones } \\
\text { (branch1) }\end{array}$ & 9 & 10.0 .7 .0 & 10.0 .7 .15 & 28 \\
\hline $\begin{array}{l}\text { Number of } \\
\text { phones } \\
\text { (branch2) }\end{array}$ & 9 & 10.0 .8 .0 & 10.0 .8 .15 & 28 \\
\hline $\begin{array}{l}\text { Number of } \\
\text { phones } \\
\text { (branch3) }\end{array}$ & 9 & 10.0 .9 .0 & 10.0 .9 .15 & 28 \\
\hline $\begin{array}{l}\text { Number of } \\
\text { servers }\end{array}$ & 4 & 10.0 .10 .0 & $\begin{array}{c}10.0 .10 .1 \\
5\end{array}$ & 28 \\
\hline
\end{tabular}

\section{CONFIGURATIONS OF THE PROJECT}

In cisco pocket tracer, there are four steps in the configurations to implementation of project network consist of: 


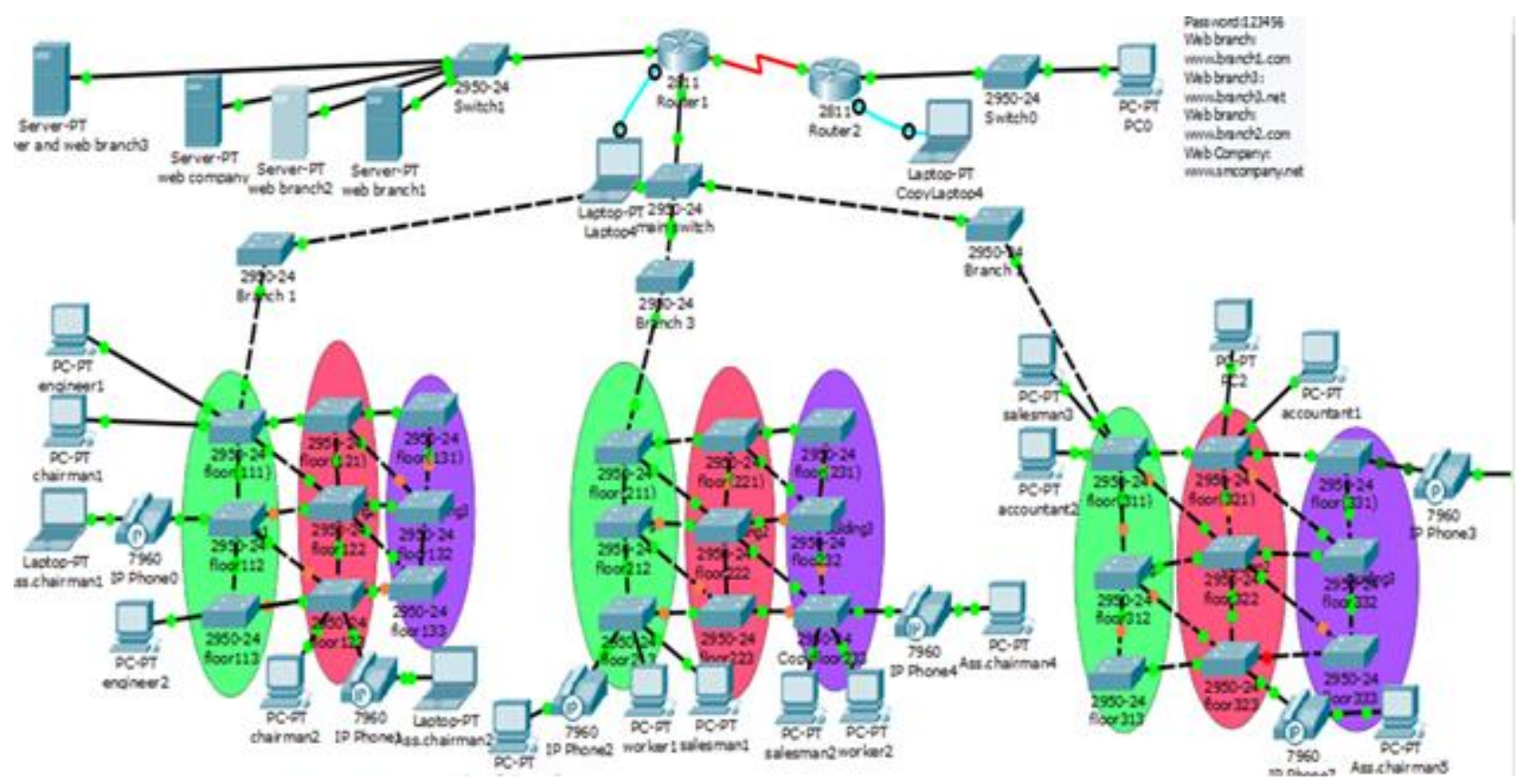

Figure (1): The scenario of the project (company)

\subsection{Switching Configuration}

In the main Switch configuration as illustrated in figure (1), in the beginning set the name of the switch (main switch) and then enable the secret password of all lines (console and auxiliary and vty lines) in the switch. The main switch is made as VTP server mode and set VTP domain to be able to create, modify, and delete VLANs because any change made to a switch in server mode will be propagated throughout the VTP domain. Each of the VLANs is defined as name. The commands show running-configuration, VTP and VLAN are used to explain all configurations of the main switch as illustrated in figure (2).

The secondary switches are defined as VTP client mode in the same domain of VTP server and all Ethernet interfaces are divided among VLANs. The mode of connections between switches is set as tracking mode but the connections between the switch and PC are access mode. Figure (3) shows all these configurations.

\subsection{Router Configuration}

Router1 considers the controlled exchange of the information between several of buildings and other routers in different places. First of all, the router1 is also renamed and supported with secret password of all lines (console and auxiliary and vty lines). The router1 is connected to the other switch using subnetinerfaces on port Ethernet interface 0/0 and all the IP networks of VLANs are added. Figure (4) presented the configurations of router1.

As shown in figure (5), EIGRP protocol routing is used to achieve the connection between router 1 and router 2 by listing the IP network. The serial interfaces ( $\mathrm{s} 0 / 0 / 0$ and $\mathrm{s} 0 / 0 / 1)$ must be gave IP address.

\subsection{Phones Configuration}

In the phone configuration, the router1 created DHCP pool with name (as voice1) and defined the IP network of the DHCP and IP default router1. The configuration of the telephone service in router1 must be defined the maximum numbers of the directory numbers, maximum numbers of phoned IP address source, automaticity assign number to bottoms phones and gave number of each phones as shown in figure (6). The mode of connections between the switch and phones is a voicing mode.

\subsection{Servers Configuration}

There are four servers used to design four websites as illustrated figure (1). All of the websites are defined in the (DNS and branch3) server by clicking it and go to DNS option in service tab and then add the name and IP address of all websites as shown in figure (7). While the other servers will add only the name and IP address of one website. The DHCP option in the server tab is added the IP address of the DNS servers and IP address of default gateway. The router1 made the DHCP pool with name server to can be called the website by PC as illustrated in figure (8). Figure (9) shows the PC calling one of the websites.

\section{CONCLUSION}

The pocket tracer is used to implement the network of the project and clarity the conception of the VLANs, DHCP, phone, website server and router configurations. Networking devices are expensive so the pocket tracer is easy and best to implement structure of the network before implementing it on the real ground. Also in the paper, the VLANs provide the security, broadcast control and physical layer transparency while VTP reduce configuration and integrate VLAN management for any changing on VTP server then it will distributed to other switches in the same VTP domain therefore the time of configuration the same VLAN is reduce. 


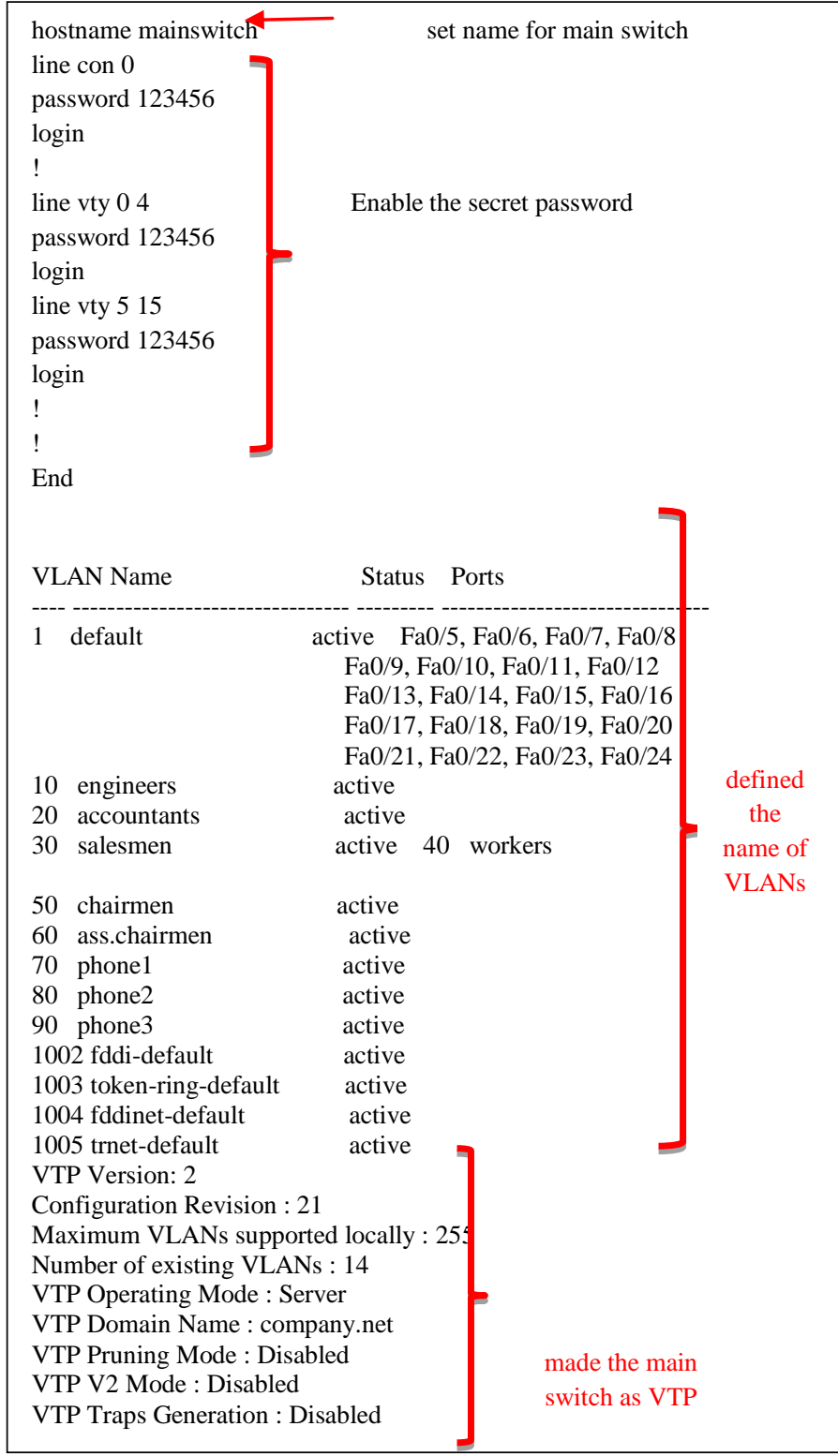

Figure (2): The Configuration of the Main Switch

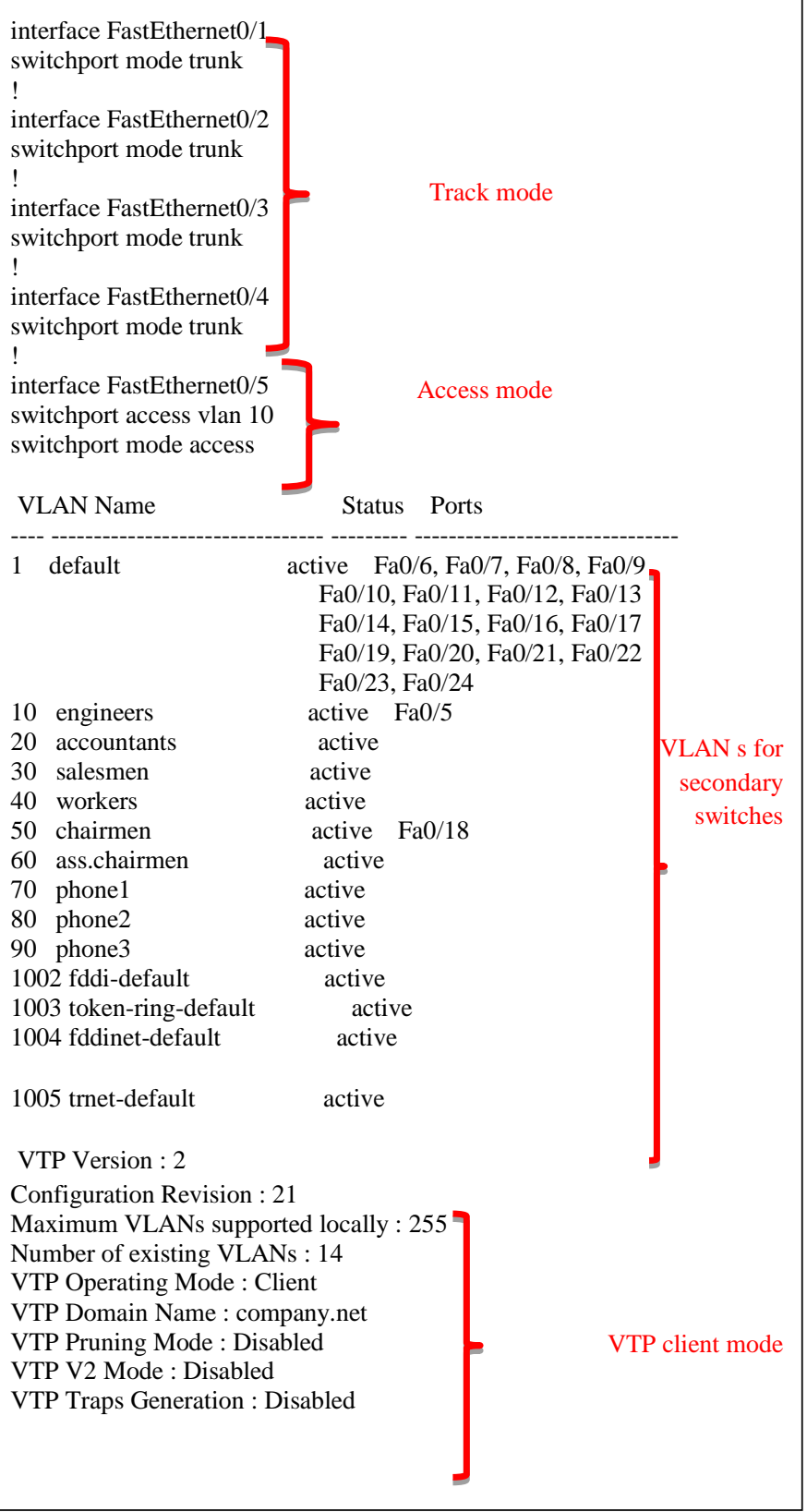

Figure (3): The Configuration of the Secondary Switches 


\begin{tabular}{|c|c|}
\hline $\begin{array}{l}\text { hostname companynet } \\
\text { line con } 0 \\
\text { password 123456 } \\
\text { login } \\
! \\
\text { line aux 0 } \\
\text { password 123456 } \\
\text { login } \\
! \\
\text { line vty 0 4 } \\
\text { password 123456 } \\
\text { login } \\
\text { line vty 5 15 } \\
\text { password 123456 } \\
\text { login } \\
\text { interface FastEthernet0/0.10 } \\
\text { encapsulation dot1Q 10 } \\
\text { ip address 10.0.0.1 255.255.254.0 } \\
! \\
\text { interface FastEthernet0/0.20 } \\
\text { encapsulation dot1Q 20 } \\
\text { ip address 10.0.2.1 255.255.255.0 } \\
! \\
\text { interface FastEthernet0/0.30 } \\
\text { encapsulation dot1Q 30 } \\
\text { ip address 10.0.3.1 255.255.255.0 } \\
\text { interface FastEthernet0/0.40 } \\
\text { encapsulation dot1Q 40 } \\
\text { ip address 10.0.4.1 255.255.255.128 } \\
! \\
\text { interface FastEthernet0/0.50 } \\
\text { encapsulation dot1Q 50 } \\
\text { ip address 10.0.5.1 255.255.255.240 } \\
! \\
\text { interface FastEthernet0/0.60 } \\
\text { encapsulation dot1Q 60 } \\
\text { ip address 10.0.6.1 255.255.255.240 } \\
! \\
\text { interface FastEthernet0/0.70 } \\
\text { encapsulation dot1Q 70 } \\
\text { ip address 10.0.7.1 255.255.255.240 } \\
! \\
\text { interface FastEthernet0/0.80 } \\
\text { encapsulation dot1Q 80 } \\
\text { ip address 10.0.8.1 255.255.255.240 } \\
! \\
\text { interface FastEthernet0/0.90 } \\
\text { encapsulation dot1Q 90 } \\
\text { ip address 10.0.9.1 255.255.255.240 }\end{array}$ & $\begin{array}{l}\text { Sub interfacing on port } \mathrm{f} \\
0 / 0 \text { to connect the } \\
\text { router } 1 \text { to other switches }\end{array}$ \\
\hline
\end{tabular}

Figure (4): The Configuration of the Router1

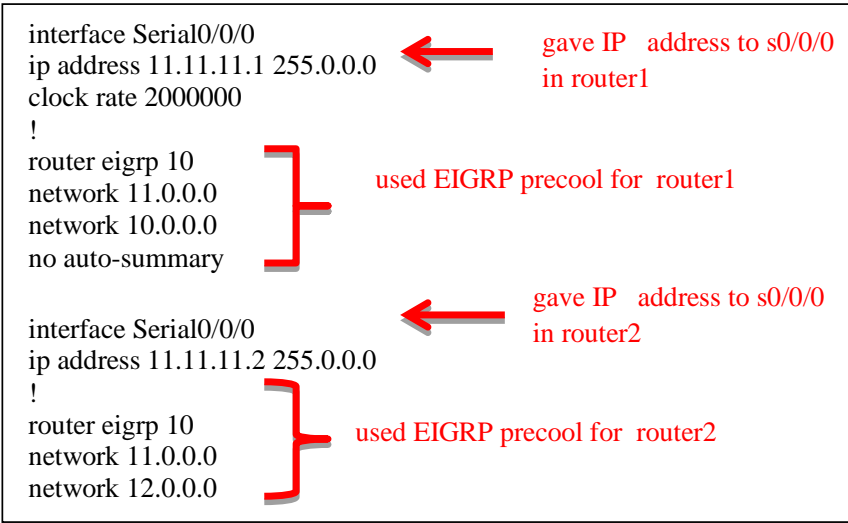

Figure (5): The Configuration of the ERGRP Protocol of Router1 and Router2

ip dhcp pool voice1
network 10.0 .7 .0255 .255 .255 .240
default-router 10.0.0.1
option 150 ip 10.0.0.1
ip dhcp pool net1
network 10.0 .6 .0255 .255 .255 .240
default-router 10.0.0.1
option 150 ip 10.0.0.1
ip dhcp pool voice2
network 10.0 .8 .0255 .255 .255 .240
default-router 10.0 .0 .1
option 150 ip 10.0 .0 .1
ip dhcp pool voice3
network 10.0 .9 .0255 .255 .255 .240
default-router 10.0 .0 .1
option 150 ip 10.0 .0 .1
telephony-service
max-ephones 9
max-dn 9
ip source-address 10.0 .7 .1 port 2000
auto assign 1 to 9
!
ephone-dn 3
number 1234
!
ephone-dn 4
number 1235
! pool
ephone-dn 5
number 1233
!
ephone-dn 6
number 1244
!
ephone-dn 7
number 123456
ephone-dn 1
number 123458
!

Figure (6): The Configuration of the Phone Service in Router1 


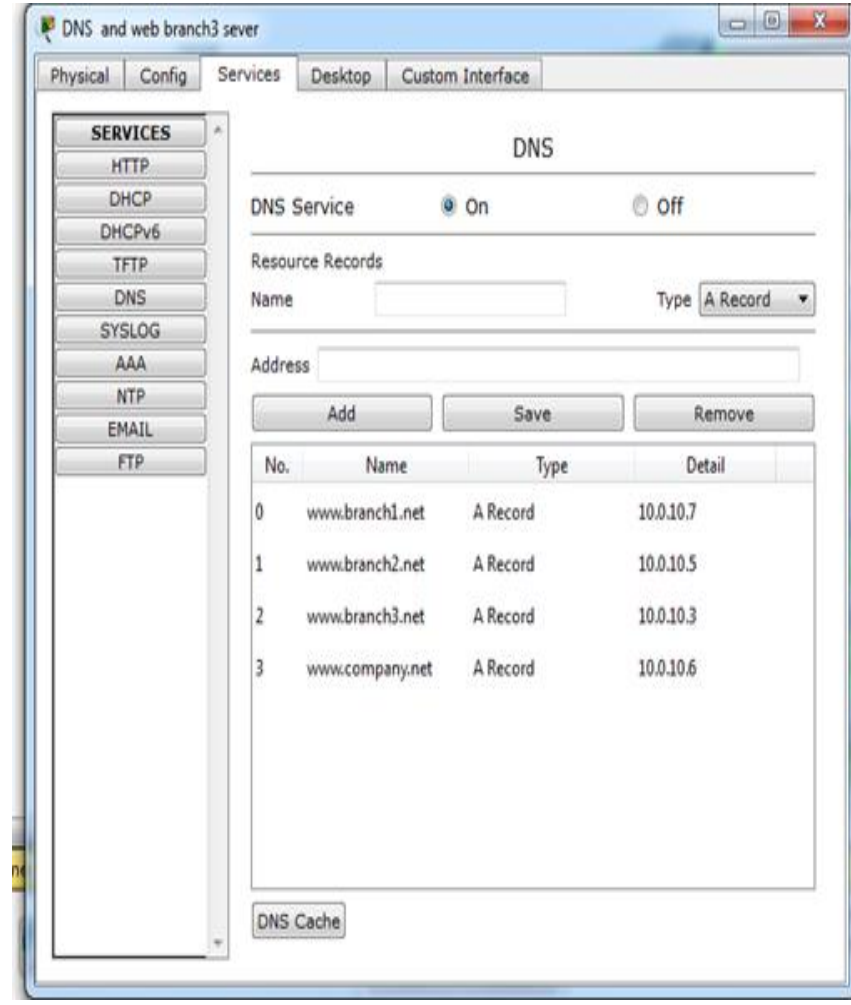

Figure (7): The windows of the (DNS and branch3) server

ip dhcp pool servers

network 10.0.10.0 255.255.255.240

default-router 10.0.0.1

Figure (8): The Configuration of the Servers in Router1

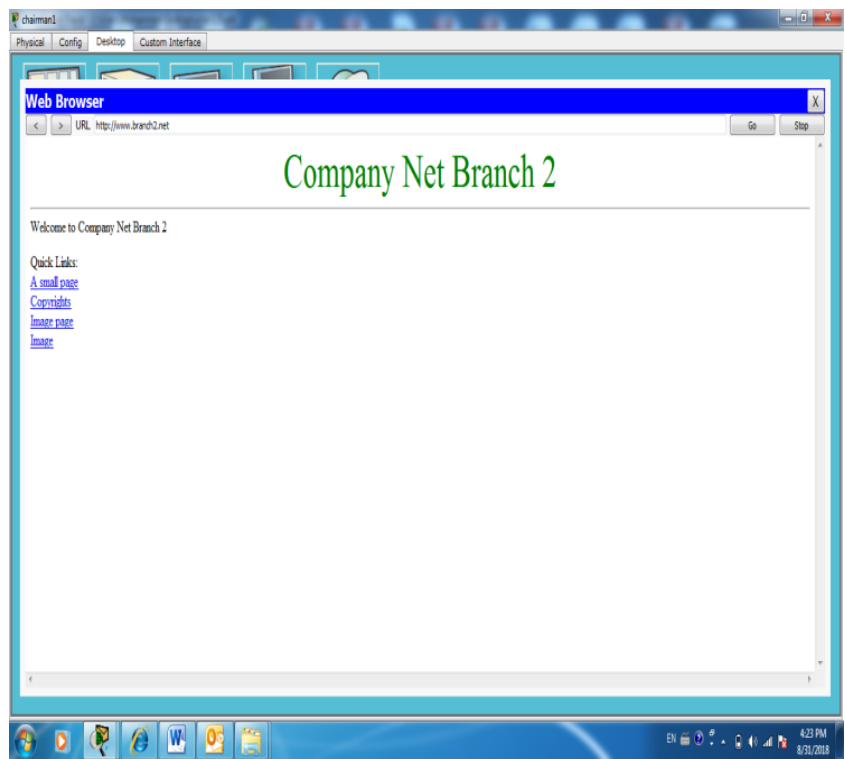

Figure (9): Calling Website (branch2) from PC

\section{REFERENCES}

[1] Behrouz A. Fourouzan, "Data Communications and Networking", fourth edition, 2007.

[2] Nathaniel S. Tarkaa, Paul I. Iannah, IsaacT. Iber "design and simulation of local area network using cisco pocket tracer", the International Journal of Engineering and Science (IJES), volume 6, issue 10, page 63-77, 2017.

[3] Edward E. Ogheneovo, Ibiba S." Modeling Network Router, Switches, And Security Using Cisco And OPNET Simulation Software" International organization of scientific Research (IOSR) of computer Engineering,volume 4, issue 7, July 2014.

[4] Todd Lammle, "CCNA", sixth Edition.

[5] Garima Jain, Nasreen Noorani, Nisha Kiran, Sourabh Sharma "Desgining and Simulation of Topology Network Using Pocket Tracer", International Research Journal of Engineering and Technology (IRJET), volume 2, issue 2,may 2015.

[6] Paulami Pathak, Sayanti Majumder, Chandra mondal, prof. Manikandan K "College Network Scenario Implementation by Using Cisco Pocket Tracer", International Journal of Advance Research in Computer and Communication Engineering (IJARCCE), volume 7, issue 1, January 2017.

[7] Sayed Mansoor hashimi, AliGunes "Performance Evaluation of Network Using Simulation Toolsor Pocket Tracer", International organization of scientific Research (IOSR) of computer Engineering, volume19, issue 1, Jan.- Feb. 2017.

[8] Sheikh Raashid Javid,"Role of Pocket tracer in learning Computer Network" International Journal of Advance Research in Computer and communication Engineering (IJARCCE), volume 3, issue 5, May 2014. 